\title{
CFD AND EXPERIMENTAL APPROACH ON THREE PHASE GAS-LIQUID-SOLID NEWTONIAN FLUID FLOW IN HORIZONTAL PIPES
}

\author{
RASEL A SULTAN ${ }^{1}$, SERAG ALFAREK $^{1}$, M. A. RAHMAN ${ }^{2} \&$ SOHRAB ZENDEHBOUDI $^{1}$ \\ ${ }^{1}$ Faculty of Engineering and Applied Science, Memorial University of Newfoundland, Canada. \\ ${ }^{2}$ Petroleum Engineering Program, Texas A\&M University, Qatar.
}

\begin{abstract}
This study analyses three dimensional fluid flow through horizontal pipelines with three-phase gasliquid-solid Newtonian fluids by Computational Fluid Dynamics (CFD) simulation. Validating the simulation with experimental data, the study aims to develop a versatile acceptable simulation model that can be used further for different applied cases. An experimental setup is developed in our laboratory to determine slug flow (air-water) through a horizontal pipeline. Air as gas, water as liquid and silica as solid particle is used in this work. ANSYS Fluent version 16.2 is employed to perform the simulation. The Eulerian multiphase model with the Reynolds Stress Model (RSM) turbulence closure is adopted to analyse multiphase fluid flow. Parameters are selected from experimental works to validate the simulation. After a good agreement with experimental data, sensitivity analysis is conducted to observe the three phase fluid flow characteristics through horizontal flow. Pressure gradient (pressure drop per unit length) and in situ concentration profile are used as primary parameters. This article provides a clear relationship between the different parameters of three-phase fluid flow through a horizontal pipeline. Keywords: CFD, experimental setup, pipeline, pressure gradient, slug flow, slurry flow, three phase flow.
\end{abstract}

\section{INTRODUCTION}

Flow through pipelines or annuli has a great impact and is widely applied in the oil and gas industry to recover produced formation from deep water or core [1]. Multiphase phase gasliquid-solid flow has been applied from the beginning.

Liquid-solid two-phase slurry flow has been applied to the transport of raw materials, waste and sludge which are in solid form, coal processing plants, fluidized beds, food and chemical plants, the petroleum industry and many more. The slurry transportation system helps to reduce traffic, air pollution, noise and accidents along with providing savings on energy consumption and lesser ecological disturbance.

On the other hand, slug flow is caused by aerated slugs of liquid that flow down a pipeline at the same velocity as the gas. Many different operations in an oil field can be at the root of slugging, such as pigging, start-up, blow-down and general transient effects. These problems can occur in the chemical and process industries or in thermo-hydraulic engineering for nuclear power plants, but our focus here is on oil and gas production. Slug initiation, including slug initiation prediction, has been studied by several researchers. In one study, slug initiation prediction is determined by analysing the stability of a stratified flow in a pipeline [6]. At the same time, the computational fluid dynamics (CFD) method, is also being applied to investigate the behaviour of two-phase flows [7].

Adding solid particles in the two-phase air-water flow reduces drag, that helps the pipeline system by saving pumping power, increasing flow rate or decreasing size of the pump and has a cost-saving effect [8]. Adding air or air injection in the two-phase slurry system also reduces the pumping cost in oil-fields [9]. There are very few studies and limited research in this field with three phase air-water-gas flow. Some of those studies are by Scott and Rao (1971) [7], 
Toda et al. (1978) [8], Fukuda and Shoji (1986) [9], Kago et al. (1986) [10], Toda and Konno (1987) [11] Gillies et al. (1997) [12], Mao et al. (1997) [2], Bello et al. (2010) [13], Rahman et al. (2013) [14] and Pouranfard et al. (2015) [8]. These are all experimental studies, mainly focused on measuring pressure gradient, deposition velocity, in situ concentration of each phase for a wide range of operating conditions. CFD simulation related works are very rare and constitute a new addition in this field. For numerical simulation studies with solid-liquidgas three phase flow, see Annaland et al. (2005) [5], Washino et al. (2011) [16] and Liu et al. (2015) [20].

The literature of three-phase flow in pipeline or annuli shows meager interest among researchers. Very few experimental and empirical studies of three-phase flow are available [18]. Those few works represent a narrow range of operating conditions and are incomplete due to having the minimum number of measurements. In some studies pressure drop and velocity profile are measured but there is no flow regime information, while other studies have an in situ gas solid concentration profile but no pressure loss information.

In this study, comparisons of CFD simulation with experimental studies are performed in different conditions and ranges with horizontal pipes. A few experiments are conducted in a flow loop installed in the fluid mechanics facility at Memorial University. Pressure readings at the inlet and outlet of certain geometry are obtained via a sensor, which transmits the signal to software capable of monitoring pressure as well as other parameters like temperature and flow rate. After verifying our simulation model, sensitivity analysis is conducted with a wide range of variables to minimize the limitation of applications in real life.

\section{NUMERICAL PROCEDURE}

The Eulerian granular model has been adopted as a multiphase model for the present study. The selection of an appropriate multiphase model depends mainly on the range of the volume fraction $(\alpha)$ of the solid phase under consideration. Since high value of volume fractions is used in this study this model is taken into account.

The description of multiphase flow as interpenetrating continua incorporates the concept of phasic volume fractions, denoted here by $a_{q}$.

The volume of phase $q, V_{q}$, is defined by:

$$
V_{q}=\int a_{q} d V
$$

where,

$$
\sum_{q=1}^{n} a_{q}=1
$$

The effective density of phase $q$ is:

$$
\hat{\rho}_{q}=a_{q} \rho_{q}
$$

where, $\rho_{q}$ is the physical density of phase $q$.

The equations for fluid-fluid and granular multiphase flows, are presented here for the general case of an $\mathrm{n}$-phase flow.

The volume fraction of each phase is calculated from a continuity equation as below:

$$
\frac{1}{\rho_{r q}}\left\{\frac{\partial}{\partial t}\left(a_{q} \rho_{q}\right)+\nabla \cdot\left(a_{q} \rho_{q} \overrightarrow{\vartheta_{q}}\right)=\sum_{p=1}^{n}\left(\dot{m}_{p q}-\dot{m}_{q p}\right)\right\}
$$


where, $\rho_{r q}$ is the phase reference density, or the volume averaged density of the $q^{\text {th }}$ phase in the solution domain, $\dot{m}_{p q}$ characterizes the mass transfer from the $p^{\text {th }}$ to $q^{\text {th }}$ phase and $\dot{m}_{q p}$. characterizes the mass transfer from the $q^{\text {th }}$. to $p^{\text {th }}$. phase.

The conservation of momentum for a fluid phase $q$. is:

$$
\begin{aligned}
\frac{\partial}{\partial t}\left(a_{q} \rho_{q} \overrightarrow{\vartheta_{q}}\right) & +\nabla \cdot\left(a_{q} \rho_{q} \overrightarrow{\vartheta_{q}} \overrightarrow{\vartheta_{q}}\right)=-a_{q} \nabla \mathrm{p}+\nabla \cdot \bar{\tau}_{q}+a_{q} \rho_{q} \vec{g} . \\
& +\sum_{p=1}^{n}\left\{K_{p q}\left(\overrightarrow{\vartheta_{p}}-\overrightarrow{\vartheta_{q}}\right)+\dot{m}_{p q} \overrightarrow{\vartheta_{p q}}-\dot{m}_{q p} \overrightarrow{\vartheta_{q p}}\right\} \\
& +\left(\overrightarrow{F_{q}}+\vec{F}_{l i f t, q}+\vec{F}_{v m, q}\right)
\end{aligned}
$$

Here, $\vec{g}$ is the acceleration due to gravity, $\bar{\tau}_{q}$ is the $q^{\text {th }}$ phase stress-strain tensor, $\vec{F}_{q}$ is an external body force, $\vec{F}_{l i f t, q}$ is a lift force, and $\vec{F}_{v m, q}$ is a virtual mass force.

Following the work of Alder and Wainwright (1960) [19] and Syamlal et al. (1993) [20], a multi-fluid granular model is used to describe the flow behaviour of a fluid-solid mixture.

The conservation of momentum for the solid phases is:

$$
\begin{aligned}
& \frac{\partial}{\partial t}\left(a_{s} \rho_{s} \overrightarrow{\vartheta_{s}}\right)+\nabla \cdot\left(a_{s} \rho_{s} \overrightarrow{\vartheta_{s}} \vec{\vartheta}_{s}\right)=-a_{s} \nabla \mathrm{p}-\nabla p_{s}+\nabla \cdot \bar{\tau}_{s} \\
& \sum_{l=1}^{N}\left\{K_{l s}\left(\overrightarrow{\vartheta_{l}}-\overrightarrow{\vartheta_{s}}\right)+\dot{m}_{l s} \overrightarrow{\vartheta_{l s}}-\dot{m}_{s l} \overrightarrow{\vartheta_{s l}}\right\}+\left(\overrightarrow{F_{s}}+\vec{F}_{l i f t, s}+\vec{F}_{v m, s}\right) \\
&+\left(\overrightarrow{F_{s}}+\vec{F}_{l i f t, s}+\vec{F}_{v m, s}\right)
\end{aligned}
$$

where, $p_{s}$ is the $s^{\text {th }}$ solids pressure, $K_{l s}=K_{s l}$ is the momentum exchange coefficient between fluid or solid phase $l$ and solid phase $s$, and $N$ is the total number of phases.

Previous studies and literature indicate few comparisons between all the turbulence models like Reynolds-averaged Navier-Stokes (RANS) models: $\mathrm{k}-\varepsilon, \mathrm{k}-\omega$ and Reynolds stress model (RSM) and Large eddy simulation (LES) for steady fluid flow through pipelines or annuli $[21,22]$. Among all these turbulence models, the Reynolds stress model (RSM) is optimum to use for turbulence flow through a simple pipe. An analysis of different turbulence models is conducted using data from Kaushal et al. (2005) [23] to find the optimum model for further investigations. In Fig. 1, single phase water velocity of $1 \mathrm{~m} / \mathrm{s}$ is maintained through horizontal pipeline. The analysis shows the RSM as the most optimum model with least error. Considering the above points turbulent quantities for fluid flow are assumed using RSM. Abandoning the isotropic eddy-viscosity hypothesis, the RSM closes the Reynolds-averaged Navier-Stokes equation by solving the transport equations for the Reynolds stresses, together with an equation for the dissipation rate.

The exact transport equation for the Reynolds stress model (RSM) is as below:

$$
\underbrace{\frac{\partial}{\partial t}\left(\rho \overline{u_{i}^{\prime} u_{j}^{\prime}}\right)}_{\text {Local Time Derivative }}+\underbrace{\frac{\partial}{\partial x_{k}}\left(\rho u_{k} \overline{u_{i}^{\prime} u_{j}^{\prime}}\right)}_{\text {Convection }\left(c_{i j}\right)}=\underbrace{-\frac{\partial}{\partial x_{k}}\left[\rho u_{k} \overline{u_{i}^{\prime} u_{j}}+\overline{p\left(\delta_{k j} u_{i}^{\prime}+\delta_{i k} u_{j}^{\prime}\right)}\right]}_{\text {Turbulent Diffusion }\left(D_{T, i j}\right)} .
$$




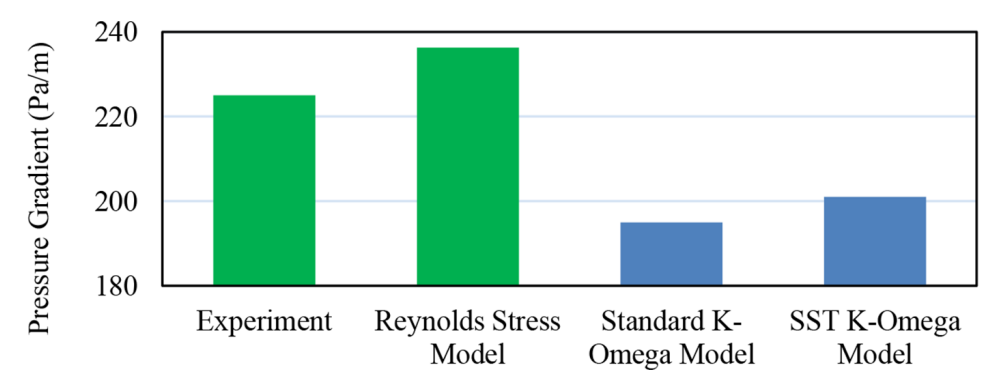

Figure 1: Optimum turbulence model analysis.

$$
\begin{gathered}
\underbrace{\frac{\partial}{\partial x_{k}}\left[u \frac{\partial y}{\partial x_{k}}\left(\overline{u_{i}^{\prime} u_{j}^{\prime}}\right)\right]}_{\text {Molecular Diffusion }\left(D_{L, i j}\right)}-\underbrace{\rho \overline{u_{i}^{\prime} u_{k}^{\prime}} \frac{\partial u_{j}}{\partial x_{k}}+\overline{u_{j}^{\prime} u_{k}^{\prime}} \frac{\partial u_{j}}{\partial x_{k}} \underbrace{\rho \beta\left(g_{i} \overline{u_{j}^{\prime} \theta}+g_{i} \overline{u_{i}^{\prime} \theta}\right)}_{\text {Buoyancy Production }\left(G_{i j}\right)}}_{\text {Stress Prouction }\left(P_{i j}\right)} \\
+\underbrace{p\left(\frac{\partial u_{i}^{\prime}}{\partial x_{j}}+\frac{\partial u_{j}^{\prime}}{\partial x_{i}}\right)}_{\text {Pressure Strain }\left(\phi_{i j}\right)}-\underbrace{2 \mu \frac{\partial u_{i}^{\prime}}{\partial x_{k}} \frac{\partial u_{j}^{\prime}}{\partial x_{k}}}_{\text {Dissipation }\left(\epsilon_{i j}\right)} \\
\underbrace{-2 \rho \Omega_{k}\left(\overline{u_{j}^{\prime} u_{m}^{\prime}} \epsilon_{i k m}+\overline{u_{i}^{\prime} u_{m}^{\prime}} \epsilon_{j k m}\right)}_{\text {Production by system Rotation }\left(F_{i j}\right)}+\underbrace{S_{\text {user }}}_{\text {User-Defined Source }}
\end{gathered}
$$

Of the various terms in these exact equations, $C_{i j}, D_{L, i j}, P_{i j}$ and $F_{i j}$ do not require any modelling. However, $D_{T, i j}, G_{i j}$, $\phi_{i j}$ and $\epsilon_{i j}$ need to be modelled to close the equations. $D_{T, i j}$ can be modelled by the generalized gradient-diffusion model of Daly and Harlow (1970) [24]:

$$
D_{T, i j}=C_{s} \frac{\partial}{\partial x_{k}}\left(\rho \frac{k \overline{u_{k}^{\prime} u_{i}^{\prime}}}{\epsilon} \frac{\partial \overline{u_{i} u_{j}^{\prime}}}{\partial x_{l}}\right)
$$

The expression for $G_{i j}$ for ideal gases is as follows:

$$
G_{i j}=-\frac{\mu_{t}}{\rho P r_{t}}\left(g_{i} \frac{\partial \rho}{\partial x_{j}}+g_{j} \frac{\partial \rho}{\partial x_{i}}\right)
$$

where, $P r_{t}$ is the turbulent Prandtl number for energy, with a default value of 0.85 used in the simulation.

The pressure-strain term, $\phi_{i j}$, is modelled according to the proposal by Gibson and Launder (1978) [25], and Launder (1989) [26].

The classical approach to modelling $\phi_{i j}$ uses the following decomposition:

$$
\phi_{i j}=\phi_{i j, 1}+\phi_{i j, 2}+\phi_{i j, w}
$$

where, $\phi_{i j, 1}$ is the slow pressure-strain term, also known as the return-to-isotropy term, $\phi_{i j, 2}$ is the rapid pressure-strain term, and $\phi_{i j, w}$ is the wall-reflection term. 
The dissipation tensor, $\epsilon_{i j}$, is modelled as:

$$
\epsilon_{i j}=\frac{2}{3} \delta_{i j}\left(\rho \in+Y_{M}\right)
$$

where, $Y_{M}=2 \rho \in M_{t}^{2}$ is an additional "dilatation dissipation" term according to the model by Sarkar and Lakshmanan (1991) [27].

\section{EXPERIMENTAL PROCEDURE}

The existing flow loop at Memorial University is a 65-meter pipe open-cycle system. The liquid can be pumped from the tank through the DN 80 (3-inch pipe). The experimental flow loop set-up starts with an approximately 5-m-long clear horizontal test section, followed by 5-m-vertical clear section and a consecutive variable inclination of a 3-m test section. These horizontal, vertical and inclined pipe sections are installed in transparent PVC pipe for visualization. Instrumentation includes several pressure and temperature sensors and flow meters for the gas and pipe line to measure the individual gas and liquid flow rates. The air injection pipe is split into two different sizes, DN 15 (0.5 inch) and DN 25 (1 inch), for different volumes of air flow. Electro-pneumatic control valves are installed in the liquid and airline to facilitate control of the flow conditions and to generate different flow regimes. The control of a flow loop is implemented through a fully integrated online computer system, which also handles the data acquisition. Here in this work, data for air-water two phase slug flow through a horizontal test section will be used. Figure 2 shows the experimental setup.

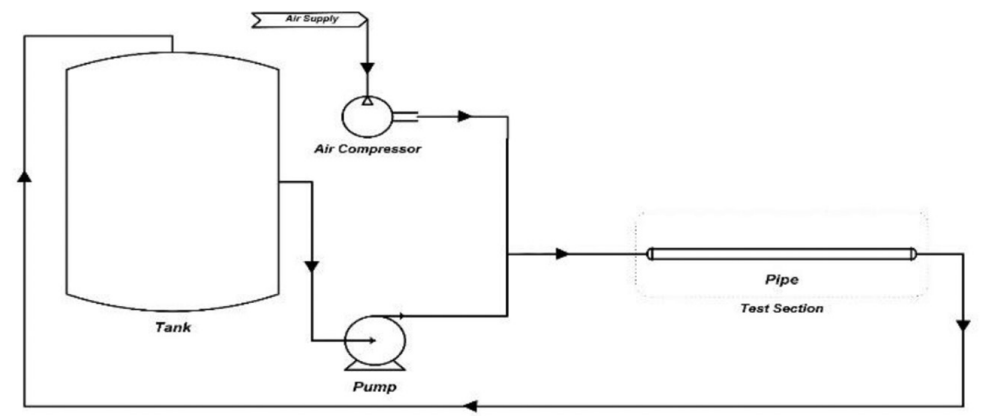

(a)

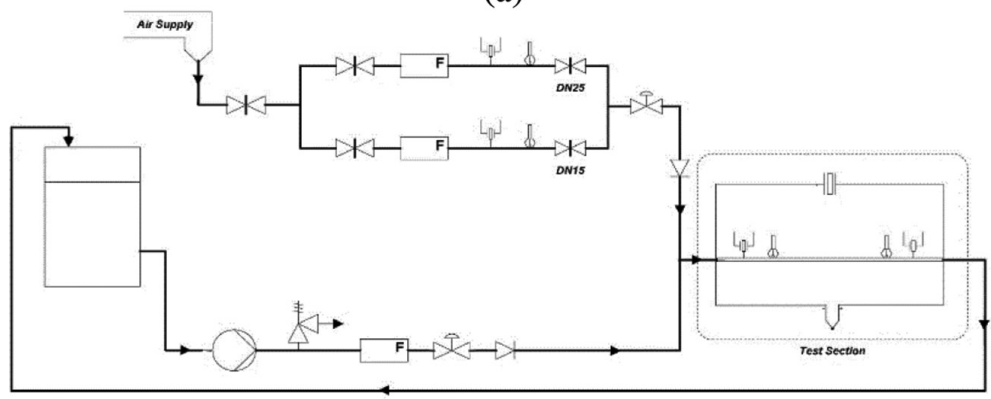

(b)

Figure 2: Experimental set-up of the multiphase flow loop. (a) Simplified diagram; (b) Schematic diagram. 
Table 1: Symbols used in flow loop (P\&ID legend).

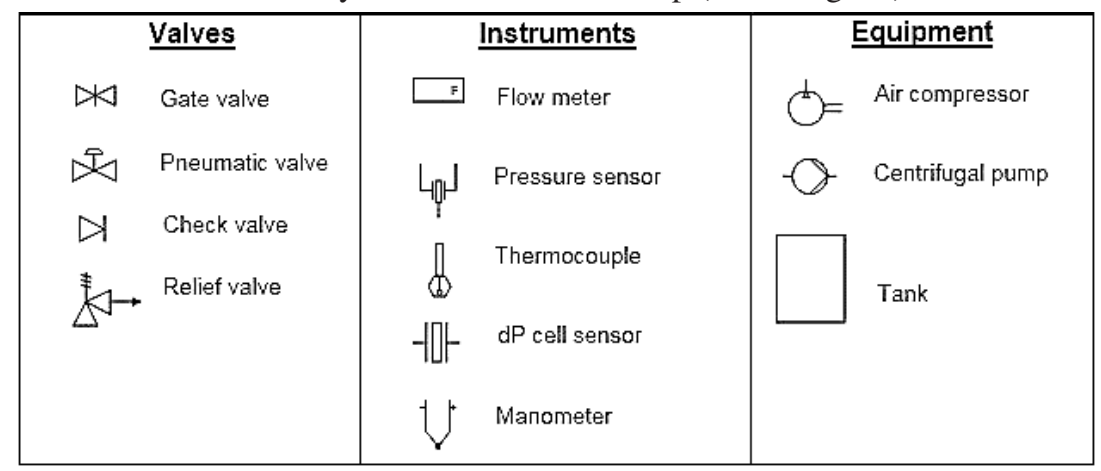

Table 1 lists the symbols used to outline the experimental set-up.

\section{SIMULATION METHODOLOGY}

The computational grids for horizontal pipe are generated using ANSYS Fluent. Meshing is finalized after conducting proper mesh independency check. Inflation is added near the wall to observe more preciously the characteristics of different parameters near the wall. Shear stress between wall surface and gas molecules is much higher and this inflation helps to create denser meshing near wall. The length of the pipe is sufficient enough in this study to achieve a fully developed flow at the outlet as minimum flow development section should be at least 50D ( $\mathrm{D}=$ internal diameter of pipe) [28]. One of the computational grid distributions of the pipe geometry is shown in Fig. 4.

ANSYS Inc. Fluent, ver. 16.2, ANSYS Inc. is used to build a CFD simulation model of pipeline flow. A convergence value of $10^{-5}$ has been adopted for termination of iteration, this value is selected by optimizing analysis to have the most satisfactory accuracy with less time. Figure 3 shows an analysis to discover the optimum convergence rate (between a range of $10^{-4}$ to $10^{-6}$ ) using parameters (inlet velocity) from the experiment. SIMPLE algorithm is applied with the first and second order upwind discretization method to have stability and confirm convergence in the governing equations. Upwind discretization is a method that simulates numerically the direction of the normal velocity in the flow field.

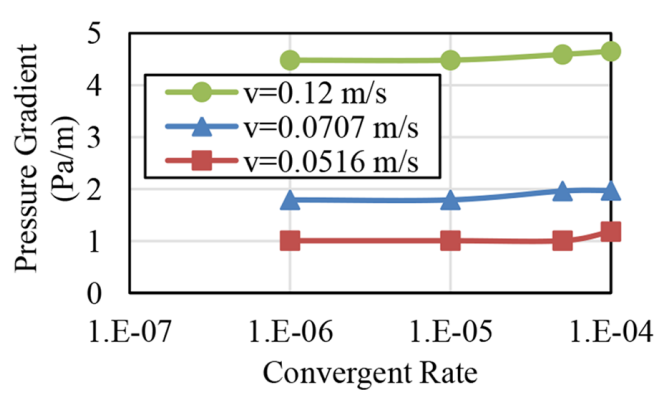

Figure 3: Optimum convergence rate analysis.

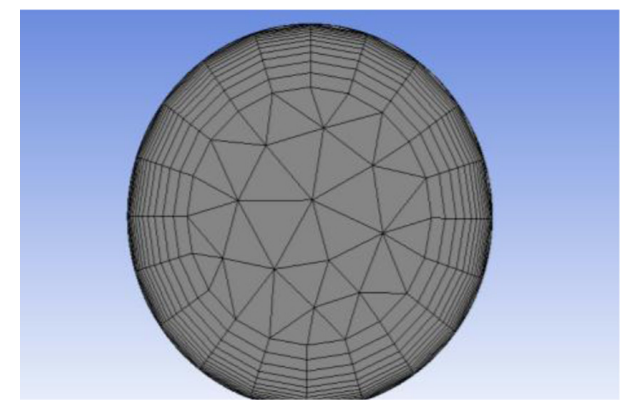

Figure 4: Mesh distribution (cross section). 


\section{RESULT AND DISCUSSION}

\subsection{Validation}

Two-phase air-water slug flow through an experimental flow loop at our laboratory is used to validate the CFD model. The data acquisition system used in the flow loop was designed by using Lab-VIEW 7.0. The program has a graphical user interface; Lab-VIEW interprets the incoming signals from the flow meter, thermocouple and pressure sensors. Geometry and other parameters in the CFD simulation are used according to experimental setup described in the experimental procedure section. Fluid are taken : water (density $998.2 \mathrm{Kg} / \mathrm{m}^{3}$, viscosity $0.001 \mathrm{Kg} / \mathrm{m}$-s) and air (density $1.225 \mathrm{~kg} / \mathrm{m}^{3}$, viscosity $1.789 * 10^{-5} \mathrm{Kg} / \mathrm{m}-\mathrm{s}$ ). Figure 5 demonstrates the pressure gradients are different for different water inlet velocity with constant gas inlet velocity $(0.69 \mathrm{~m} / \mathrm{s})$.

The local solid concentration profile of water-sand slurry flow from the simulation is compared with Roco and Shook's (1983) [29] experimental data in Fig. 6. Here, the length of the pipe is $13.15 \mathrm{~m}$, its diameter is $263 \mathrm{~mm}$, fluid is taken : water (density $998.2 \mathrm{Kg} / \mathrm{m}^{3}$, viscosity $0.001003 \mathrm{Kg} / \mathrm{m}$-s) and slurry taken silica (chemical formula $\mathrm{SiO}_{2}$, density $2650 \mathrm{Kg} / \mathrm{m}^{3}$ ) and

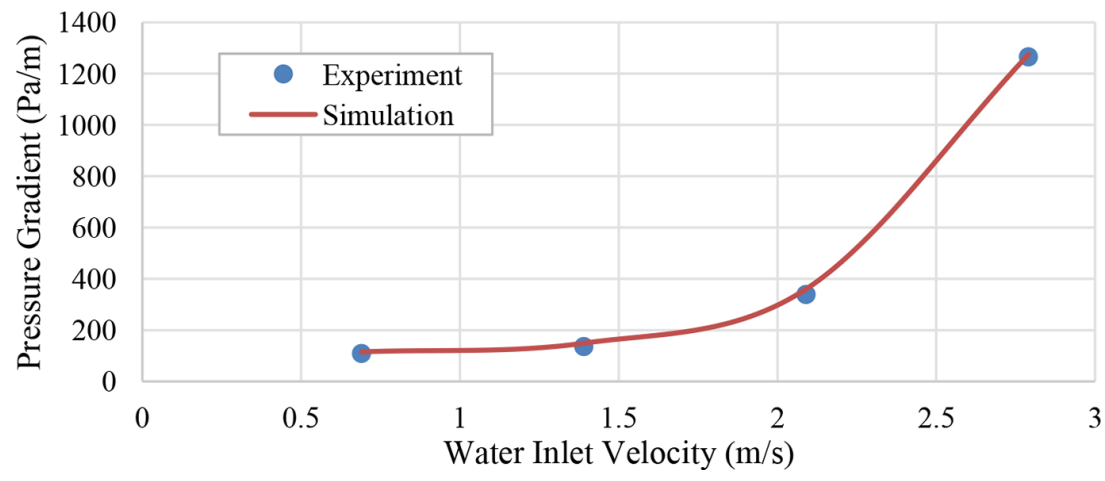

Figure 5: Comparison of pressure gradient as a function of water velocity.



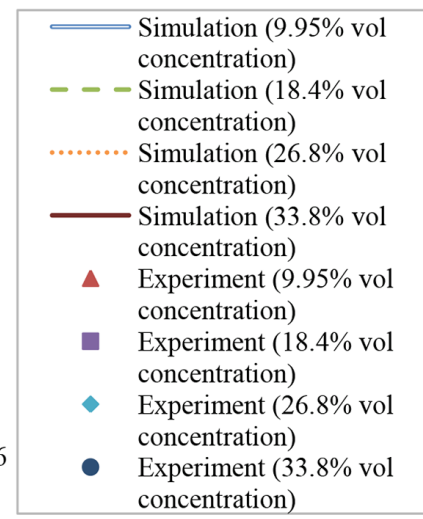

Figure 6: Comparison of simulated and measured values of local volumetric concentration of solid across vertical centreline. 
wall material is aluminum (density $2800 \mathrm{~kg} / \mathrm{m}^{3}$, roughness $0.2 \mathrm{~mm}$ ). Grain size or mean particle diameter is $0.165 \mathrm{~mm}$ with mixture velocity $3.5 \mathrm{~m} / \mathrm{s}$ and four different solid volumetric concentrations: $9.95 \%, 18.4 \%, 26.8 \%$ and $33.8 \%$ respectively.

The simulated results are in good agreement with the experimental values. However, the simulated values deviate from the experimental values. One possible reason for these deviations could be the approximate value of the static settled concentration (packing limit) used during simulations, as the value of 0.63 used is best suited to finer grain sizes only.

The pressure gradient of air-water-sand three-phase flow from the simulation is compared with Fukuda and Shoji's (1986) [12] experimental data. In the experiment length of the pipe is $2.9 \mathrm{~m}$, its diameter is $0.0416 \mathrm{~m}$, fluid are taken : water (density $998.2 \mathrm{Kg} / \mathrm{m}^{3}$, viscosity $0.001 \mathrm{Kg} / \mathrm{m}-\mathrm{s}$ ), silica sand particle (density $2650 \mathrm{~kg} / \mathrm{m}^{3}$, mean particle diameter $74 \mu \mathrm{m}$ ) and air (density $1.225 \mathrm{~kg} / \mathrm{m}^{3}$, viscosity $1.789 * 10^{-5} \mathrm{Kg} / \mathrm{m}$-s). The pipe wall material is polycarbonate pipe (transparent, smooth pipe). Figure 7 shows a comparison of the pressure gradient with the solid volume concentration $\left(\mathrm{C}_{\mathrm{v}}\right): 24.7 \%$ in slurry and $3 \mathrm{~m} / \mathrm{s}$ slurry velocity at different gas velocities. In Fig. 7, the average deviation of simulation data from experimental data is $2.1 \%$, considering each point with maximum $4.26 \%$ error at $1.36 \mathrm{~m} / \mathrm{s}$ gas velocity in the pipeline. This shows very good agreement (comparable error) with experiment.

\subsection{Parametric Analysis}

After demonstrating very good and acceptable agreement of simulation with reference experimental results, the approach is to analyse the flow behaviour at different condition of independent parameters that affect multiphase flow through pipelines. In situ concentrations of solid and diameter of pipeline are considered here as independent variables that can affect flow behaviour.

Figure 8 shows the two-phase water-slurry flow contours of the local volumetric concentration distribution of the solid phase in the vertical plane at the outlet cross-section for particle size of slurry $0.165 \mathrm{~mm}$ and mixture velocity of $3.5 \mathrm{~m} / \mathrm{s}$ at different efflux concentrations of solid slurry. From contour analysis it is clear that the region of highest solid concentration is located very near to the wall in the lower half of the pipe cross section. This happened due to the effect of gravity in horizontal pipeline which can lead to finding out the deposition velocity (i.e. minimum superficial velocity of mixture to prevent accumulation of solids or waste in the pipeline).

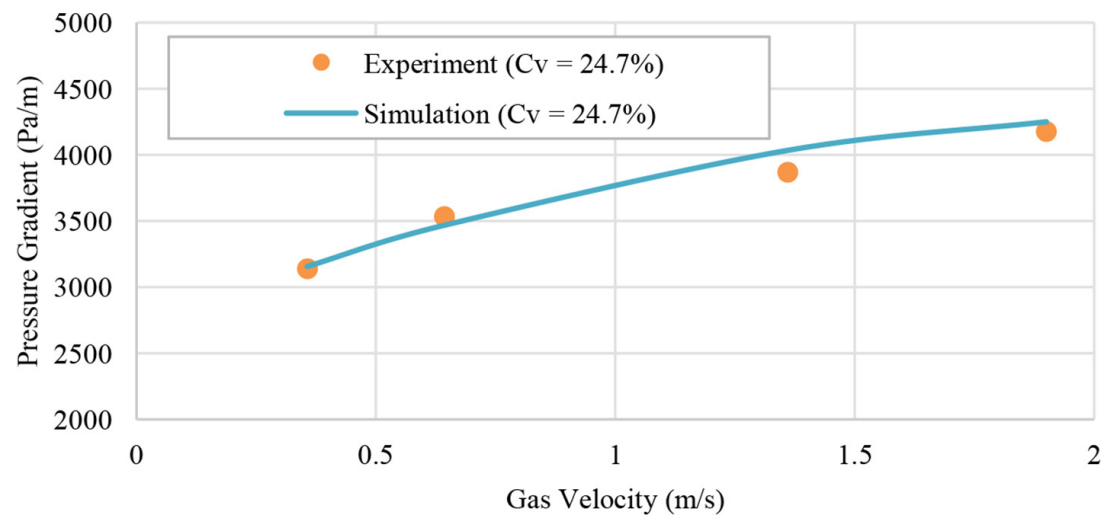

Figure 7: Comparison of pressure gradient as a function of gas velocity. 




(a) Solid volumetric concentration $9.95 \%$

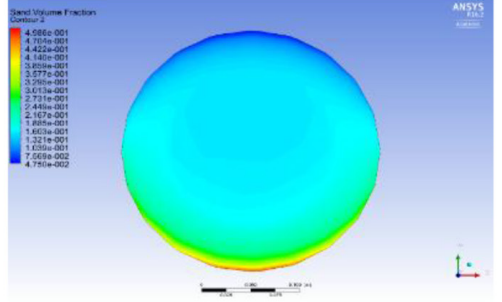

(b) Solid volumetric concentration $18.4 \%$

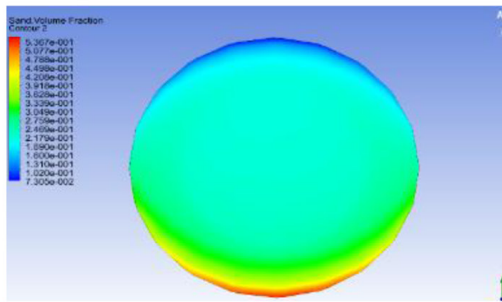

(c) Solid volumetric concentration $26.8 \%$



(d) Solid volumetric concentration $33.8 \%$

Figure 8: Solid concentration distribution in the vertical plane at the outlet

Keeping sand in situ concentration in slurry, fluid viscosity and pipe wall roughness constant in three phase air-water-slurry flow, Fig. 9 graphically describes the change of pressure gradient with the change in internal pipe diameter (D) and gas velocity.

The Darcy-Weisbach equation [30] is as follows:-

$$
\Delta P=\frac{f L}{D} \frac{\rho v^{2}}{2}
$$

where, $\Delta P$ is pressure drop, $f$ is friction factor, $L$ is pipe length, $D$ is internal diameter of the pipeline, $\rho$. is fluid density and $v$ is fluid velocity.

According to Eqn, (12), the pressure gradient decreases with the increase in internal pipe diameter, with the other parameters constant and the relation is inversely proportional. The increasing rate of pressure gradient is lower for smaller pipe diameters but the trend of the



Figure 9: Pressure gradient at different gas velocity anpipe diameter. 
increasing rate is almost the same. The pipeline should not be manufactured with a diameter size lower than a specific limit, which produces a maximum level of pressure drop required by industry.

\section{CONCLUSION}

This CFD simulation approach to multiphase flow through a horizontal pipeline demonstrates some good agreements and outcomes, with reference to experimental works. With the aim of building a model that can be applied in practical problems with fewer parameter boundary limitations, some analysis is performed under different conditions, after validating the developed model. A few of the approaches are listed below:

- Building a CFD model with Eulerian multiphase and RSM turbulence closure to simulate multiphase flow through a horizontal pipeline.

- Discussing the numerical explanation of CFD modelling and its assumptions with valid references.

- Demonstrating, with a diagram, an experimental flow loop which is sited in our laboratory.

- Simulating two-phase water-air slug flow and comparing with our own experiment.

- Validating two-phase water-sand slurry flow with reference to the experimental data.

- Validating three-phase air-water-sand flow with reference the experimental data; this also demonstrates the effect of adding air into two-phase slurry flow.

- Conducting a few parametric studies with two-phase and three-phase flow. Contour distribution of the in situ concentration of sand and pressure gradient are used as output parameters to analyse the effects of changing parameters. The output shows similarity with developed theories and empirical correlations.

The study is ongoing with parametric analysis. CFD errors need to be reduced by focusing more on the choice of different coefficients and constants such as the coefficient of lift, coefficient of drag, restitution coefficient and wall boundary conditions. The effect of vibration due to fluid flow will be a future task for this project.

\section{ACKNOWLEDGEMENTS}

The authors wish to acknowledge the Faculty of Engineering and Applied Science of Memorial University and ANSYS Inc. for help during this project.

\section{REFERENCES}

[1] Geilikman, M.B. \& Dusseault, M.B., Fluid rate enhancement from massive sand production in heavy-oil reservoirs. Journal of Petroleum Science and Engineering, 17(1), pp. 5-18, 1997. https://doi.org/10.1016/s0920-4105(96)00052-6

[2] Mao, F., Desir, F.K. \& Ebadian, M.A., Pressure drop measurement and correlation for three-phase flow of simulated nuclear waste in a horizontal pipe. International Journal of Multiphase Flow, 23(2), pp. 397-402, 1997. https://doi.org/10.1016/s0301-9322(96)00061-4

[3] Al-Lababidi, S., Addali, A., Yeung, H., Mba, D. \& Khan, F., Gas void fraction measurement in two-phase gas/liquid slug flow using acoustic emission technology. Journal of Vibration and Acoustics, 131(6), p. 064501, 2009.

https://doi.org/10.1115/1.4000463 
[4] Czapp, M., Utschick, M., Rutzmoser, J. \& Sattelmayer, T., Investigations on slug flow in a horizontal pipe using stereoscopic particle image velocimetry and CFD simulation with volume of fluid method. In 2012 20th International Conference on Nuclear Engineering and the ASME 2012 Power Conference (pp. 477-486). American Society of Mechanical Engineers, 2012.

[5] Pouranfard, A.R., Mowla, D. \& Esmaeilzadeh, F., An experimental study of drag reduction by nanofluids in slug two-phase flow of air and water through horizontal pipes. Chinese Journal of Chemical Engineering, 23(3), pp. 471-475, 2015. https://doi.org/10.1016/j.cjche.2014.11.023

[6] Sanders, R., Schaan, J. \& McKibben, M., Oil sand slurry conditioning tests in a 100 mm pipeline loop. Canadian Journal of Chemical Engineering, 85(5), pp. 756-764, 2007.

https://doi.org/10.1002/cjce.5450850521

[7] Scott, D.S. \& Rao, P.K., Transport of solids by gas-liquid mixtures in horizontal pipes. The Canadian Journal of Chemical Engineering, 49(3), pp. 302-309, 1971. https://doi.org/10.1002/cjce.5450490302

[8] Toda, M., Shimazaki, K. \& Maeda, S., Pressure drop of three-phase flow in horizontal pipes. Kagaku Kogaku Ronbunshu, 4, pp. 56-62, 1978.

https://doi.org/10.1252/kakoronbunshu.4.56

[9] Fukuda, T. \& Shoji, Y., Pressure drop and heat transfer for tree phase flow: 1st report, flow in horizontal pipes. Bulletin of JSME, 29(256), pp. 3421-3426, 1986. https://doi.org/10.1299/jsme1958.29.3421

[10] Kago, T., Saruwatari, T., Kashima, M., Morooka, S. \& Kato, Y., Heat transfer in horizontal plug and slug flow for gas-liquid and gas-slurry systems. Journal of Chemical Engineering of Japan, 19(2), pp. 125-131, 1986.

https://doi.org/10.1252/jcej.19.125

[11] Toda, M. \& Konno, H., Fundamentals of gas-liquid-solid three phase flow. Japanese Journal of Multiphase Flow, 1(2), pp. 139-156, 1987. https://doi.org/10.3811/jjmf.1.139

[12] Gillies, R.G., McKibben, M.J. \& Shook, C.A., Pipeline flow of gas, liquid and sand mixtures at low velocities. Journal of Canadian Petroleum Technology, 36(09), 1997. https://doi.org/10.2118/97-09-03

[13] Bello, O.O., Udong, I.N., Falcone, G. \& Teodoriu, C., Hydraulic analysis of gas/oil/ sand flow in horizontal wells. In SPE Latin American and Caribbean Petroleum Engineering Conference. Society of Petroleum Engineers, 2010.

[14] Rahman, M.A., Adane, K.F. \& Sanders, R.S., An improved method for applying the Lockhart-Martinelli correlation to three-phase gas-liquid-solid horizontal pipeline flows. The Canadian Journal of Chemical Engineering, 91(8), pp. 1372-1382, 2013. https://doi.org/10.1002/cjce.21843

[15] Annaland, M., Deen, N.G. \& Kuipers, J.A.M., Numerical simulation of gas-liquidsolid flows using a combined front tracking and discrete particle method. Chemical Engineering Science, 60(22), pp. 6188-6198, 2005.

https://doi.org/10.1016/j.ces.2005.04.038

[16] Washino, K., Tan, H.S., Salman, A.D. \& Hounslow, M.J., Direct numerical simulation of solid-liquid-gas three-phase flow: fluid-solid interaction. Powder Technology, 206(1), pp. 161-169, 2011.

https://doi.org/10.1016/j.powtec.2010.07.015 
[17] Liu, X., Aramaki, Y., Guo, L. \& Morita, K., Numerical simulation of gas-liquid-solid three-phase flow using particle methods. Journal of Nuclear Science and Technology, 52(12), pp. 1480-1489, 2015. https://doi.org/10.1080/00223131.2015.1012132

[18] Orell, A., The effect of gas injection on the hydraulic transport of slurries in horizontal pipes. Chemical Engineering Science, 62(23), pp. 6659-6676, 2007. https://doi.org/10.1016/j.ces.2007.07.067

[19] Alder, B.J. \& Wainwright, T.E., Studies in molecular dynamics. II. Behavior of a small number of elastic spheres. The Journal of Chemical Physics, 33(5), pp. 1439-1451, 1960.

https://doi.org/10.1063/1.1731425

[20] Syamlal, M., Rogers, W. \& O'Brien, T.J., MFIX documentation: Theory guide (Technical Note DOE/METC-95/1013 and NTIS/DE95000031). National Energy Technology Laboratory, Department of Energy, Washington, DC, 1993. https://doi.org/10.2172/10145548

[21] Vijiapurapu, S. \& Cui, J., Performance of turbulence models for flows through rough pipes. Applied Mathematical Modelling, 34(6), pp. 1458-1466, 2010. https://doi.org/10.1016/j.apm.2009.08.029

[22] Markatos, N.C., The mathematical modelling of turbulent flows. Applied Mathematical Modelling, 10(3), pp. 190-220, 1986. https://doi.org/10.1016/0307-904x(86)90045-4

[23] Kaushal, D.R., Sato, K., Toyota, T., Funatsu, K. \& Tomita, Y., Effect of particle size distribution on pressure drop and concentration profile in pipeline flow of highly concentrated slurry. International Journal of Multiphase Flow, 31(7), pp. 809-823, 2005. https://doi.org/10.1016/j.ijmultiphaseflow.2005.03.003

[24] Daly, B.J. \& Harlow, F.H., Transport equations in turbulence. Physics of Fluids (19581988), 13(11), pp. 2634-2649, 1970. https://doi.org/10.1063/1.1692845

[25] Gibson, M.M. \& Launder, B.E., Ground effects on pressure fluctuations in the atmospheric boundary layer. Journal of Fluid Mechanics, 86(03), pp. 491-511, 1978. https://doi.org/10.1017/s0022112078001251

[26] Launder, B.E., Second-moment closure: present... and future? International Journal of Heat and Fluid Flow, 10(4), pp. 282-300, 1989. https://doi.org/10.1016/0142-727x(89)90017-9

[27] Sarkar, S. \& Lakshmanan, B., Application of a Reynolds stress turbulence model to the compressible shear layer. AIAA Journal, 29(5), pp. 743-749, 1991. https://doi.org/10.2514/3.10649

[28] Brown, N.P. \& Heywood, N.I. (Eds.)., Slurry Handling: Design of solid-liquid systems. Springer Science \& Business Media, The Netherlands, 1991.

[29] Roco, M.C. \& Shook, C.A., Modeling of slurry flow: the effect of particle size. The Canadian Journal of Chemical Engineering, 61(4), pp. 494-503, 1983. https://doi.org/10.1002/cjce.5450610402

[30] Brown, G.O., The history of the Darcy-Weisbach equation for pipe flow resistance. Environmental and Water Resources History, eds. A. Fredrich \& J. Rogers, American Society of Civil Engineers: Reston, Virginia, pp. 34-43, 2003. https://doi.org/10.1061/40650(2003)4 